SEssion I

INFLUENCES GÉNETIQUES ET ENVIRONNEMENTALES
SUR LES MÉCANISMES DE DÉFENSE

\title{
Genetic and environmental aspects of the immune response
}

\author{
C.C. OOSTERLEE \\ Department of Animal Husbandry, Agricultural University, «Zodiac » \\ Marijkeweg 40, Wageningen, The Netherlands
}

The main characteristic of the immune system is the potency to detect and resist invasions of foreign substances like viruses, bacteria, parasites and transformed malignant cells. This ability is characterised and determined mostly by macrophage activity and $\mathrm{T}$ and $\mathrm{B}$ lymphocytes.

These three major components of the immune response are independently genetically regulated. This makes selection on the basis of the immune response difficult.

Environmental factors can induce stress situations with a too high corticosteroid blood level. Corticosteroids can be immunosuppressive. In modern animal husbandry practice such factors exist and can influence disease resistance resulting into multifactorial diseases.

\section{Genetic studies of immunological traits in goats}

\author{
T. ALMLID \\ Department of Animal Genetics and Breeding, \\ Agricultural University of Norway, $\stackrel{\circ}{\text { s }-N L H, ~ N o r w a y ~}$
}

The design and the results from the first three years of an experiment with two-way selection for antibody response in goats are described. Selection is based on performance testing of young kids. By the testing the animals are injected three different antigens against which the humoral and cellular immune response are being quantified. The primary antibody response against diphtheria toxoid is used as the sole selection criterion.

The preliminary data indicate relatively great genetic influence on the quantitative antibody response. After two years of selection the males of the High response line show a significantly higher humoral response than the Low response line to all three antigenes injected. High responder animals are significantly superior over low responder animals throughout the whole course of the immune response period studied. Significantly positive correlations have been demonstrated between humoral and cellular immune response parameters. 